\title{
La responsabilidad social empresarial en la relación comunidades campesinas y empresas mineras
}

\section{Corporative Social Responsibility Within the Relationship Peasant Communities - Mining Companies}

María Isabel Medrano Sánchez* https://orcid.org/0000-0003-4766-101X José Luis Masías Vidal** https://orcid.org/0000-0003-2151-3676

Jessica Karina Obeso Cuadra*** https://orcid.org/0000-0002-3545-2686 Geraldo Morón Paredes**** https://orcid.org/0000-0002.4290-8215 Wendy Lidia Moreano Márquez ${ }^{* * * * *}$ https://orcid.org/0000-0002-2070-9055 María

Eugenia García Segovia****** https://orcid.org/0000-0002-7881-5299 José Coveñas Lalupu******* https://orcid.org/0000-0001-5318-9618 http://dx.doi.org/10.21503/lex.v17i23.1681

Abogada. Magíster en Derecho de la Minería. Docente e Investigadora de la Facultad de Derecho y Ciencia Política de la Universidad Alas Peruanas (Lima, Perú) del curso de Derecho Minero e Hidrocarburos; Medio Ambiente y Desarrollo Sostenible y Coordinadora de la Mención de Minería y Medio Ambiente. Asesora temática de tesis. Consultora en Minería y Medio Ambiente.

**_Correo electrónico: isabel@medrano.pe ; m_medrano@doc.uap.edu.pe

Ingeniero ambiental. Maestro en Docencia Universitaria y Gestión Educativa. Especialista en Monitoreo y Evaluación de la Calidad Ambiental y en Seguridad y Salud en el Trabajo. Coordinador académico y docente de la Escuela de Ingeniería Ambiental de la Universidad Alas Peruanas.

Correo electrónico: j_masias@uap.edu.pe

*** Abogada. Magíster en Derecho de la Minería, especialización en Derecho Ambiental, Derecho Minero e Hidrocarburos, Responsabilidad Social Empresarial. Docente de la Facultad de Derecho y Ciencia Política de la Universidad Privada Norbert Wiener (Lima, Perú) del curso Derecho Ambiental y ponente en cursos de especialización en Medio Ambiente, Desarrollo Sostenible, Seguridad y Sistemas Integrados de Gestión a nivel de postgrado.

Correo electrónico: jessicaobesoc@gmail.com; jobeso@ecospacio.com.pe

**** Ingeniero metalúrgico. Segunda especialización en Medio Ambiente, Desarrollo Sostenible y Recursos Naturales. Especialización en Alta Gerencia. MBA. Expositor de diplomados y cursos de especialización en Medio Ambiente, Desarrollo Sostenible, Seguridad y Sistemas Integrados de Gestión a nivel de postgrado. Correo electrónico: gmph26@hotmail.com

***** Ingeniera civil con maestría en Ingeniería Civil con mención en Gestión y Gerencia en la Construcción. Egresada de la maestría en Ingeniería Vial y doctoranda en Medio Ambiente y Desarrollo Sostenible. Experiencia en el sector público en temas de transportes y gestión vial en vías nacionales. Correo electrónico: wendymoreanom@hotmail.com

****** Arquitecta con estudios de maestría en Gestión Pública, delegada titular por parte del Colegio de Arquitectos del Perú en la Comisión Técnica de Edificaciones del Centro Histórico de Lima, docente de la Facultad de Arquitectura y Urbanismo de la Universidad Privada del Norte de los cursos de Urbanismo Sostenible II y III. Correo electrónico: mariaeugenialourdes@yahoo.com

******* Ingeniero Industrial, primera promoción de magísteres y primera promoción de doctores de Ing. Ind. del Perú de la Universidad Nacional Federico Villarreal (Lima, Perú), Senior Operation Systems (OSP) Researcher (Massachussets Institute of Innovation and Reinvention), conferencista nacional e internacional en temas de Medio Ambiente, responsabilidad social y cultural, premiado por la Unesco Puerto Rico, Embajador de la Paz Mundial con sede en Ginebra, Suiza, miembro del Colegio y de la Sociedad de ingenieros del Perú, investigador.

Correo electrónico: jocola2003@gmail.com

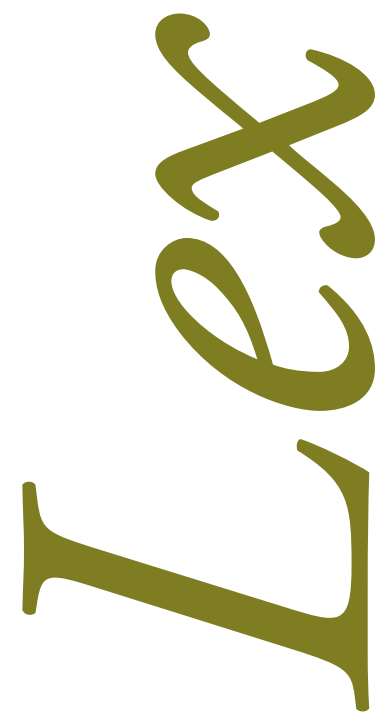




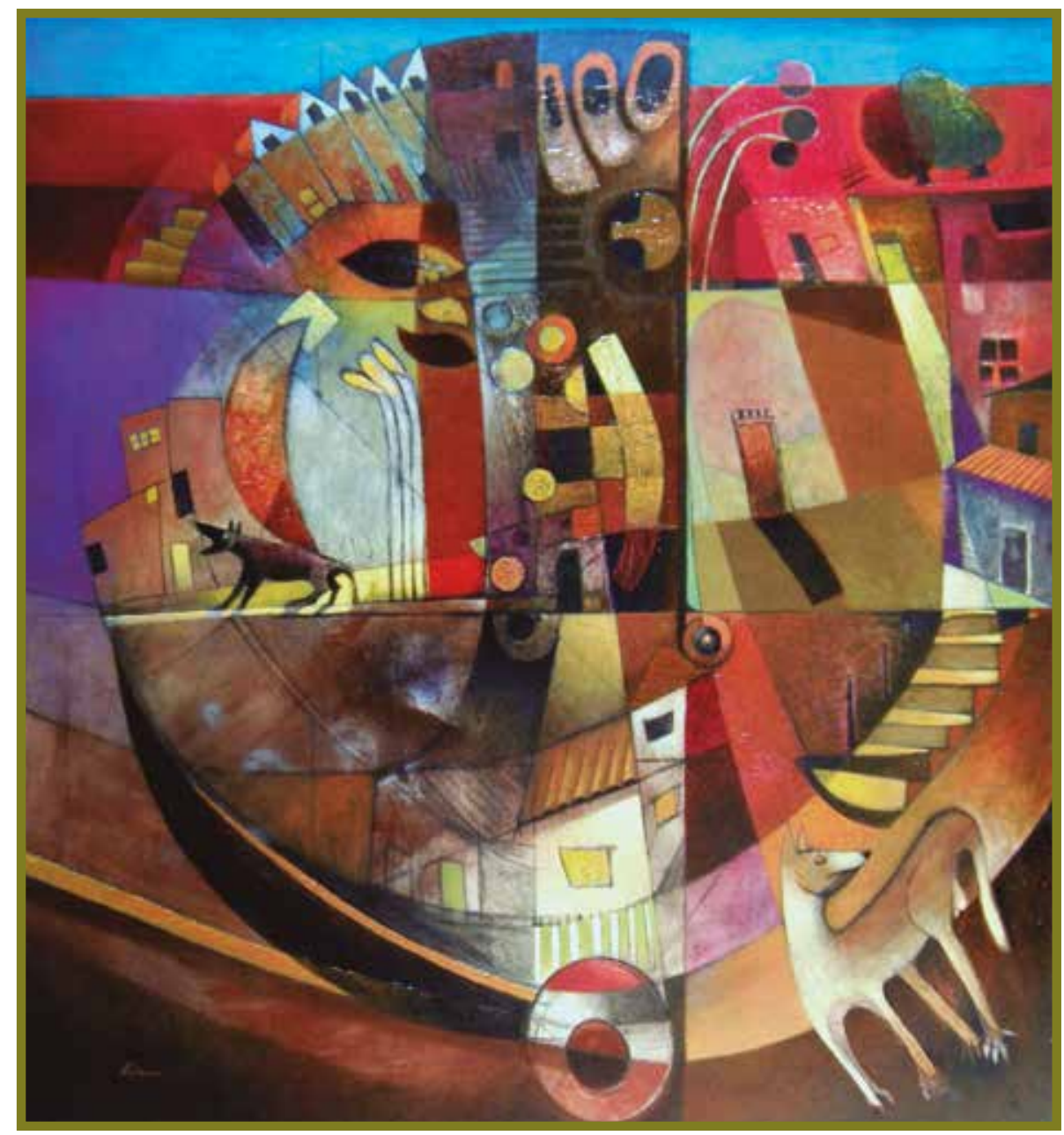

Homenaje a Arguedas. Óleo 152 x 158 cm.

Agustín Aquino Mejías (pintor peruano). 


\section{RESUMEN}

El artículo pretende hacer una aproximación a la responsabilidad social empresarial desde el enfoque empresas mineras versus el entorno que las rodea, como eje estratégico para alcanzar una línea de negocio social y ambientalmente sostenible. El objetivo de la investigación fue determinar las prácticas de responsabilidad social empresarial gestionadas por la actividad minera formal, analizándolas desde su dimensión ambiental y económica a fin de identificar qué criterios o acciones de responsabilidad social faltan fortalecer y si se evidencian fallas o desviaciones en el cumplimiento de normas y políticas por parte de los titulares mineros en relación con el cuidado del medio ambiente y el desarrollo económico local. Se analizan los alcances de la (i) responsabilidad social y de (ii) la industria minera, para comprender necesidades y requerimientos de las comunidades y poblaciones en esta relación. Se recomienda involucrar a las empresas mineras y a la comunidad en alianzas estratégicas con una visión de desarrollo sostenido, donde ambos ganen, considerando que este vínculo debe generar valor, más allá de la vida misma de la operación minera. Bajo este orden de ideas, es necesario conocer la trayectoria y perspectiva de las comunidades, sus ejes económicos, su convivencia con la actividad minera, sus estrategias sociales para conseguir el desarrollo local en base a sus actividades económicas, considerando la ecuación: minería - economía - entorno social - medio ambiente.

Palabras clave: mineria, responsabilidad social empresarial, comunidades campesinas, medio ambiente.

\section{ABSTRACT}

The article intends to approach corporate social responsibility from the standpoint of mining companies versus its surroundings as a strategic axis to achieve a socially and environmentally sustainable business. The objective of the investigation was to determine the corporate social responsibility practices managed by the formal mining companies, analyzing them from their environmental and economic dimension in order to identify which social responsibility criteria or actions need to be strengthen and if there are flaws or deviations in compliance related to environmental care and local economic development by the mining title holders. The scope of (i) social responsibility and (ii) the mining industry are analyzed in order to understand the needs and requirements of the communities and populations within this relationship. The authors recommend binding both the mining companies and the community together in strategic alliances with sustainable development view, where both win, considering that this link must produce value beyond the very life of the mining operation.

Following these ideas, knowing the communities' history and point of view, their economic axis, their coexistence with the mining activity, their social strategies to achieve local development based on their economic activities considering the equation: mining - economy - social setting - environment.

Key words: mining, corporate social responsibility, peasant communities, environment. 


\section{INTRODUCCIÓN}

No es una ilusión mencionar la relación compleja que existe entre comunidad y empresa; este binomio nos ha tenido muy pendientes de una gran lista de conflictos sociales por todo el país que nos lleva a analizar y discutir los objetivos y alcances de la Responsabilidad Social Empresarial (en adelante RSE), entendida como un instrumento que vincula a la organización con sus trabajadores, sus familias y su entorno para que puedan trabajar sin problemas y vivir en armonía y tranquilidad, pero ¿podemos decir que se trata de un aspecto empresarial que se preocupa por la colectividad?

La RSE en el Perú ha sufrido una serie de fases y ha pasado por diversas etapas; en un primer momento se hablaba de filantropía hasta la adopción de prácticas, políticas y programas sociales en empresas pertenecientes a diversos sectores. Aún existe cierta renuencia a adoptar e internalizar prácticas de responsabilidad social en el sector minero, no obstante, un número considerable de empresas están apostando a ser socialmente responsables, sobre todo grandes empresas.

La tendencia en materia de RSE del sector privado ha sido afectada por la historia y coyuntura atravesada en el país, especialmente en las épocas del gobierno militar de 1968 y de la época del terrorismo en los años 80 , en donde la empresa privada peruana solo luchaba por su sobrevivencia y su aceptación en la sociedad. Esto ha cambiado y hoy tenemos un panorama más estable en materia económica, lo que ha permitido que las empresas puedan desarrollar programas relacionadas a la RSE e integrarlas de alguna manera con su política, objetivos y forma en su planeamiento estratégico corporativo.

Observamos que la RSE en el Perú ha ido alcanzando una serie dimensiones, las cuales se han ido generando a medida que las empresas han comenzado a identificar a sus stakeholders; en ese sentido, hoy en día se puede hablar de diferentes niveles y variedades de grupos de interés como el Estado, los proveedores, los clientes, los trabajadores, los accionistas, las ONG, la comunidad, entre otros. 
A pesar de los esfuerzos realizados en el tema de la RSE, existen aún retos y oportunidades a futuro que el sector empresarial privado debería conocer para lograr un mejor desempeño socialmente responsable, no solo a nivel de las grandes empresas, sino también de las pequeñas empresas, los medios de comunicación y la comunidad académica.

Dentro de este contexto, es interesante mencionar a Georgina Núñez R. que en su ensayo La responsabilidad social corporativa en un marco de desarrollo sostenible señala que:

La responsabilidad social corporativa ha pasado de ser una actividad estrictamente filantrópica a un elemento central de la estrategia de las empresas tendientes a la construcción de una nueva cultura corporativa. En América Latina, la llegada de empresas multinacionales y la inserción a la economía internacional de los grupos económicos regionales han acelerado el proceso.

Entonces tenemos que una empresa que trabaja en su identidad corporativa y quiere ser reconocida más allá de sus logros económicos y rentables debe ejecutar programas sociales como parte de su aporte al desarrollo sostenible de la zona donde se desarrolla. La RSE es una herramienta estratégica de gestión destinada a forjar canales de comunicación con distintos grupos de interés y construir un "lazo puente" armónico de convivencia.

Fernando Hilbck, director ejecutivo de la Fundación Backus afirma:

Una empresa socialmente responsable, que se preocupa por los demás, evidentemente se preocupa por sus trabajadores. Esto es demostrable a través de las mediciones del clima organizacional. En nuestro caso, en estas encuestas resalta el orgullo que sienten nuestros trabajadores de pertenecer a una gran empresa que se preocupa los por demás. Un ejemplo lo constituye el Programa de Voluntariado Backus, a través del cual los trabajadores realizan labores totalmente desinteresadas, disponiendo de su tiempo libre en beneficio de la comunidad.

Las entidades con programas de RSE hacen inversiones para elevar la productividad de sus integrantes y aseguran su integridad física, emocional e intelectual; adquieren nuevos equipos, los renuevan y utilizan sistemas de seguridad; crean mecanismos para recoger sugerencias de sus colaboradores; optimizan su impacto en la comunidad y en el ambiente; identifican las carencias de su colectividad y buscan satisfacerlas; efectúan cambios para suavizar situaciones de crisis y ofrecen orientaciones al trabajador a fin de encontrar oportunidades de empleo e invierten en las familias de su personal, capacitándolas o brindando atención a sus necesidades.

En el Perú y en las naciones de tercer mundo, la RSE se orienta, especialmente, a solucionar requerimientos básicos (salud, educación, infraestructura y afines). Las inversiones en programas de RSE, en zonas de extrema pobreza, en muchos casos se confunden y tienden 
a sustituir las obligaciones del Estado peruano, que como sabemos, tiene la obligación de atender estas solicitudes sobre las necesidades básicas de las poblaciones, aunque no siempre este tiene capacidad para afrontar — de forma rápida y efectiva — las demandas ciudadanas a través de los gobiernos regionales o locales y vemos que al "reemplazar" la compañía al Estado, asume un liderazgo social en la zona donde se desarrolla.

En tal sentido, existen empresas extractivas "supuestamente" cuestionadas por sus impactos ambientales negativos a la localidad, con programas en RSE, utilizados para intentar amortiguar los efectos perturbadores de sus actividades y, de esta manera, calmar las exigencias de la población, pero con el único fin de erradicar la protesta muchas veces sin fundamentos, pues no es la preocupación por el medio ambiente sino un medio de dependencia mediante para la atención de sus exigencias. Por otro lado, también vemos casos como la corporación minero metalúrgica Doe Run Perú (La Oroya) que ha ocasionado, según informes de la Organización Mundial de la Salud (OMS) que el $99 \%$ de los nińos de La Oroya tengan niveles de plomo en la sangre que exceden más de tres veces los límites permisibles en los estándares internacionales, afectando su salud y esperanza de vida. La revista Time describe a La Oroya como uno de los diez sitios más contaminados del planeta; en efecto, esto es así, pues la actividad extractiva de la corporación se dio cuando no existían normas que regulen dicha conducta.

Es conveniente que, previo a la confección de los planes de RSE, se haga un minucioso análisis de la realidad cultural y económica del área donde se desarrollará el proyecto y, además, se consulte a sus más representativos interlocutores e instituciones, pues debe entenderse también que al interior de una población o comunidad también encontramos desorden en su organización y muchos intereses individualistas que, lejos de velar por los intereses comunales o colectivos, lo hacen para favorecer sus intereses políticos propios. Encontramos que las autoridades, incluso las eclesiásticas, son los referentes a tomar en cuenta en el momento de disminuir posibles desconfianzas de los pobladores.

La coordinación y contribución mutua es invalorable en el éxito de la RSE. Por ejemplo, en la edificación de un colegio, se asumirá la aportación del pueblo — a través de la mano de obra de sus habitantes - y, por su parte, la empresa ofrecerá el diseño, los medios económicos y el equipamiento. La cooperación de los beneficiados hará realidad una obra que perdurará por encima de la permanencia de la empresa en la zona. Ese es el contraste con el asistencialismo que crea vínculos de dependencia, no favorece el desarrollo y tiene al poblador "cruzado de brazos" observando cómo la empresa "paga" a cambio de paz o de su permanencia en la zona

La RSE hoy en día propone una nueva visión de ética corporativa; las empresas entienden que la generación de dividendos financieros y utilidades está acompañada de la voluntad de respetar a los pobladores y trabajar para mejorar su reputación entre sus distintos actores a 
los que se dirige y en los diversos niveles con los que se articula. Permite humanizar el rol de la organización en la sociedad e integrarla en un escenario en donde se desenvuelve haciendo suyos los anhelos de sus habitantes. La RSE permite proyectar sus valores fuera del entorno directo de los clientes e integra aspiraciones colectivas siendo este su principal objetivo.

\section{COMUNIDADES CAMPESINAS}

Dentro de este conjunto de actores que esperan que el capital foráneo les toque de alguna manera, encontramos a las comunidades campesinas, pues en esas zonas alejadas donde se desarrolla, por lo general, la actividad extractiva y donde el Estado no tiene mucha presencia es que surgen los conflictos socioambientales frente a los programas de RSE que implementan las empresas.

Las comunidades campesinas surgen de tres elementos: un territorio, construido como colectivo a lo largo de la historia; una población, que se identifica como colectivo y con el territorio; y un proceso de reconocimiento, en el que este grupo es reconocido como tal por los vecinos, por el Estado y por otros agentes. Se reconoce como comunidades campesinas especialmente a los grupos de costa y sierra, incluso algunas en ceja de selva. Las comunidades siempre han tenido tensiones alrededor de ellas. Tensiones básicas alrededor de los intereses de las familias y de los colectivos dependiendo de las condiciones. Tensiones entre grupos de interés dentro de la comunidad: agricultores y ganaderos, o comerciantes y agricultores, católicos y evangélicos, modernos y tradicionales. En un contexto de transformación, estas tensiones se activan de otra manera, las comunidades no son un lugar detenido, sino que siempre están en tensión.

Además, la definición de lo que es un recurso comunal ha cambiado. Los recursos comunales ya no son el territorio sino los usos, ya sean agrícolas, ganaderos, hídricos, turísticos o mineros, que se hacen de él. Finalmente, el gobierno comunal es más complejo, tiene que ver con formas de autogobierno y nuevas instituciones. ${ }^{1}$

La Ley General de Comunidades Campesinas ${ }^{2}$ establece que las comunidades campesinas son organizaciones de interés público, con existencia legal y personería jurídica, integradas por familias que habitan y controlan determinados territorios, ligadas por vínculos ancestrales, sociales, económicos y culturales, expresados en la propiedad comunal de la tierra, el trabajo comunal, la ayuda mutua, el gobierno democrático y el desarrollo de actividades multisectoriales, cuyos fines se orientan a la realización plena de sus miembros y del país, indica la Ley 24656, Ley de Comunidades Campesinas.

Alejandro Diez Hurtado, Tensiones y transformaciones en comunidades campesinas (Lima: CISEPA, 2012), 14.
Ley 24656, Ley General de Comunidades Campesinas. 
Hay muchos aspectos que no están claros y que no se ciñen al precepto constitucional, por lo que hay muchas cosas que están en ley que son inconstitucionales. No es tan fácil actualizar una ley en la que hay muchos conceptos que no han sido aclarados, como comunidades campesinas, pueblos originarios, pueblos indígenas, entre otros. La Ley General de Comunidades Campesinas es una ley nacional; sin embargo, hay un grupo de elementos que hacen que las comunidades sean parecidas, pero hay otros que las hacen diferentes. Debería haber una tipología regional de las comunidades para implementar políticas más apropiadas con el tipo de población que se encuentra, pues no se pueden aplicar en una comunidad campesina en Piura las políticas que se han diseñado para una comunidad campesina en el Cusco. En la legislación se reconocen solo dos tipos de comunidades: comunidad campesina y comunidad campesina de la costa.

Los recursos de las comunidades hacen que estas comunidades sean ricas, pero estas no lo saben. Y es la dificultad de gestión lo que hace que estas comunidades puedan parecer pobres cuando en realidad no lo son. A partir de los casos se puede ver que hay comunidades que aprovechan sus recursos al máximo y otras que no lo hacen porque se encuentran en disputas internas.

\section{LA INDUSTRIA MINERA}

Es en la actividad minera donde el Estado solicita una serie de estudios que las empresas mineras tienen que cumplir para obtener una licencia ambiental. Para ello tienen que identificar los aspectos ambientales sobre los recursos, agua, aire, suelo del área donde se va a desarrollar el proyecto. No obstante, la minería actual cuenta con tecnologías que han dejado en el pasado a la minería artesanal, basada en la galería y el socavón que conducen a la veta. Estas han dado paso a los megaproyectos mineros que alteran radicalmente los ecosistemas, pues explotan a tajo abierto las menas (se denomina mena al mineral del cual se extrae el metal), moliendo masivamente la tierra y separando por lixiviación las moléculas del mineral gracias a la atracción que ejerce el cianuro de sodio. Antes los mineros extraían pepitas o la veta, hoy realizan un proceso que consiste en separar las moléculas del metal contenido en el suelo.

La actividad minera es uno de los pilares de la economía nacional y genera, en forma directa e indirecta, progreso y desarrollo económico para todo el país; sin embargo, en muchos de los casos, en las zonas alejadas donde se desarrollan los proyectos mineros, la población no siente los beneficios de la minería ni del desarrollo que esta actividad genera y es ahí donde de manera supletoria las empresas mineras, en algunos casos, contribuyen a atender las demandas de la población. Sin embargo, se sigue evidenciando conflictos y protestas sociales en torno a dicha actividad.

No obstante, las economías que tienen grandes dotaciones de recursos naturales, especialmente aquellas abundantes en minerales, como en el caso del Perú, son consideradas por la doctrina económica como poco probables de alcanzar altos niveles de desarrollo. Sobre el 
particular Perla ${ }^{3}$ ha señalado que las rentas que se originan de la extracción de los recursos minerales, que podrían utilizarse para iniciar un proceso de crecimiento económico en el país, tienen en la práctica una serie de efectos negativos que sobrepasan sus potenciales contribuciones positivas.

Discrepamos con dicha afirmación, puesto que la explotación de recursos naturales constituye una actividad productiva que genera beneficios económicos y que, a partir de una eficiente y adecuada regulación, puede originar resultados favorables respecto de la población a través de mecanismos como el canon, las regalías y ahora también el aporte voluntario. Consideramos más bien que los recursos naturales son importantes para comprender la dinámica de las economías de países en vías de desarrollo, ya que estos representan una gran parte de su producción agregada, puesto que son a menudo su principal exportación. Por ello, los recursos naturales son de especial importancia para el crecimiento de la economía del país y también para poder entender el funcionamiento de la economía de países como el nuestro.

La dotación de los recursos naturales y el terreno apto para la actividad productiva son, sin duda, factores estructurales básicos para la supervivencia de una Nación, así como la existencia de nuestra geografía, el grado de desarrollo local, la existencia de articulación territorial entre las diversas regiones del país y la cuestión de fronteras.

Nos aqueja la preocupación de que la utilización de los recursos naturales renovables y no renovables se realice sin respetar el desarrollo sostenible, que es uno de los objetivos que tiene nuestro país, ya que no solo hay que explotar los recursos naturales mediante el sistema de la concesión, sino que además hay que hacer que nuestra riqueza natural sea aprovechada de manera responsable y sostenible $y$, sobre todo, respetando nuestro medio ambiente y sin atentar contra la seguridad jurídica de nuestro sistema legal, llegar a ser un Perú sostenible; esta es una de las mayores metas sobre regulación de los recursos naturales en nuestro país.

Sabemos que el Perú es un país minero y existe una gran cantidad de proyectos mineros por ejecutar y que la actividad minera en el Perú tiene un gran impacto en su economía, sobre todo en lo referente a la recepción de divisas, mayor recaudación fiscal, generación de empleo directo e indirecto, y el desarrollo económico y social de las comunidades aledañas. Por ello, es importante analizar el dinamismo de la actividad minera, actividad extractiva por naturaleza, así como su composición y las oportunidades que genera para el Perú. Debemos ser conscientes de que puede generar un impacto en el ambiente y se debe garantizar que este impacto sea el menor posible. En todo caso, es su responsabilidad desarrollar la actividad dentro de los parámetros establecidos por la legislación ambiental.

3 Cecilia Perla, “¿Cuál es el destino de los países abundantes en recursos naturales?”, Documentos de Trabajo PUCP, n. 242 (2005): 4 y ss. 
Sin embargo, como en toda actividad que realiza el hombre, existe el riesgo de producir dańos al medio ambiente en tanto el Estado no implemente adecuadamente las regulaciones ambientales aplicables a la actividad minera, así como un sistema eficiente de control y fiscalización.

La formalidad exige cumplir con toda la normativa legal y disposiciones relacionadas a las actividades que desarrollamos para extraer el mineral y todas las actividades auxiliares y conexas. Asimismo, se deben obtener los permisos y autorizaciones requeridas para dicha actividad, para lo cual se debe tener como base la Política de Estado de fomentar una minería responsable ambiental y socialmente y cambiar la fama de la minería de antaño. La situación actual demanda, más que nunca, un tratamiento jurídico acucioso de la regulación de los recursos naturales y la protección del medio ambiente en general. Con la inserción de la temática ambiental en la regulación minera, se atendió la necesidad de que el aprovechamiento de los minerales sea realizado en forma racional y sostenida.

\section{RESPONSABILIDAD SOCIAL EMPRESARIAL}

Debido a la globalización y al progreso de la sociedad, el ámbito empresarial y el mundo de los negocios han sufrido una serie de grandes cambios e innovaciones. Sabemos que hoy en día los mercados se comportan de una forma más competitiva y sobre todo dinámica debido tanto a influencias internas como externas; de allí que reclaman una mayor participación en los procesos de toma de decisiones a nivel empresarial.

Actualmente, se nota el incremento de las demandas de una sociedad que exige una retribución por los beneficios que obtienen las organizaciones en sus líneas de negocio. La sociedad comienza a pedir cambios y cuidado cuando se desarrollen proyectos de inversión o negocios, pero sobre todo pide un mayor involucramiento del entorno empresarial en los problemas sociales; este punto es considerado desde el enfoque financiero y bancario y denota una gran importancia para el gobierno corporativo y la RSE en el sector bancario.

Martínez, Vaquero, Cuadrado y García (2015) realizaron un artículo en el que muestran una investigación conjunta de 159 bancos pertenecientes a nueve países. Allí señalan que las asociaciones de los bancos también participan en las decisiones estratégicas de estos, entre las cuales resalta el compromiso con la RSE para satisfacer las expectativas de los grupos de interés. El trabajo reveló también una influencia significativa y el impacto positivo del consejo de los bancos en el desarrollo de las prácticas de RSE en general; y de aquellas relacionadas con cuestiones sociales en particular. ${ }^{4}$

4 Jennifer Martínez, Luis Vaquero, Beatriz Cuadrado y María García, "El gobierno corporativo y la responsabilidad social corporativa en el sector bancario: El papel del consejo de administración”, Econstor 21 (2015), https://doi.org/10.1016/j. iedee.2015.01.001 
Tratar de determinar los orígenes o desde cuándo se utiliza el término de la Responsabilidad Social Empresarial no es significativo; cada autor tiene una postura diferente sobre sus inicios y, si bien algunos coinciden en ciertos aspectos de sus orígenes, la mayoría de ellos adopta posiciones contrarias.

Así tenemos a Lozano, ${ }^{5}$ que considera que el inicio de la RSE data de la publicación del libro de Adam Smith La riqueza de las naciones en 1776, sumado al impacto originado por el calvinismo "en la medida en que ambos contribuyeron a la identificación de la empresa con la maximización de los beneficios". Si esto es así, y tomamos como referencia la publicación de la obra de Smith, la RSE tendría ya un largo recorrido, lo que la convierte en una disciplina de muchos años de antigüedad bajo el criterio cronológico.

Por otro lado, tenemos a Navarro ${ }^{6}$ quien señala que "la RSE establece sus antecedentes históricos varios siglos atrás en los orígenes de las organizaciones que conjugaron capital y trabajo para generar riqueza y beneficio".

Cada autor tendrá sus razones para interpretar los orígenes de la RSE, incluso dichas razones pueden depender de la perspectiva desde que se aborde, es decir, si se toman como base las empresas privadas, o si por el contrario es una entidad pública, o una organización sin ánimo de lucro. Bajo estos parámetros, Herranz \& Salinas ${ }^{7}$ estiman que las acciones de las cajas de ahorro, a través de su obra social, son las que originaron el movimiento de la RSE. Esta posición puede ser, de alguna manera, mal interpretada por los autores, ya que no se debe confundir con el hecho de que cualquier persona natural o jurídica lleve a cabo acciones sociales de manera aislada y altruista, que en la lógica actual no puede ser considerada como una acción de RSE.

Adicionalmente, la perspectiva de Herranz \& Salinas se fundamenta desde las obras sociales de las empresas y organizaciones, lo cual genera una dificultad: si las cajas de ahorro han instaurado este tipo de acciones en su devenir diario, es porque forman parte de su razón de ser. De esta manera, se debe separar concretamente el sentido de que una organización realice acciones de responsabilidad social porque siente la necesidad de dar a la comunidad algún beneficio; o porque dichas labores sociales forman parte de su misión y su visión como empresa.

Josep M. Lozano, La empresa ciudadana como empresa responsable y sostenible (Madrid: Trotta, 2009), 82.

6 Fernando Navarro García, "Responsabilidad social corporativa: teoría y práctica”, Revista del Ministerio de Trabajo e Inmigración (2008): 47.

7 José María Herraz de la Casa y Francisco Salinas Ramos, "La comunicación en el ámbito de la economía social”, en Colección Economía Social (España: Universidad Católica de Ávila, 2004), 52. 
Siguiendo con este análisis del origen de la RSE, Cannon ${ }^{8}$ señala que el inicio de la RSE se produjo en los albores de la revolución industrial. La evolución del hombre, su desarrollo y despegue y las nuevas disposiciones económicas, sociales y políticas que introdujo la llegada de la máquina a vapor favorecieron el establecimiento definitivo de las empresas.

El crecimiento exponencial y la forma en que dichas instituciones comenzaron a ganar cada vez más terreno en la sociedad generaron circunstancias a las que no eran ajenos los ciudadanos, sobre todo desde la perspectiva de su propia relación con las empresas. Sin embargo, el nuevo poder de la empresa y, sobre todo, sus manifestaciones de grandeza no son mérito suficiente para definir en estas circunstancias el establecimiento de acciones de tipo responsable socialmente por parte de estos entes económicos. Una situación es la visión que tengan los ciudadanos sobre las obligaciones de una empresa y otra es que se dé el primer paso para una relación de mutua colaboración.

Como vemos, no hay consenso entre diversos investigadores sobre el momento exacto en que surge la RSE. Se puede advertir que son varios los momentos y múltiples las razones y circunstancias por las que ha pasado este concepto para convertirse en la Responsabilidad Social Empresarial que significa hoy en día en los ámbitos académicos y empresariales.

Si bien no podemos llegar a establecer con exactitud criterios bien definidos sobre la evolución de la RSE de manera oficial, sí podemos establecer algunos hitos en la historia que originaron un cambio en el comportamiento de las empresas y organizaciones y que algunos autores denominan como posibles etapas por las que la RSE ha ido desarrollándose.

En uno de los casos, se toma como base estudios de otros investigadores para señalar la existencia de seis etapas:

\section{FIGURA N ${ }^{\circ}$ 1. HITOS HISTÓRICOS-SEIS ETAPAS RSE}
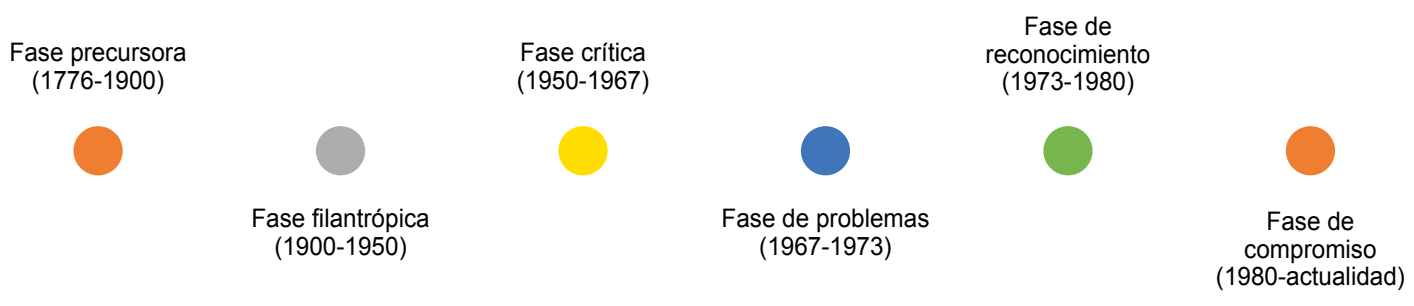

Fuente: Garrigues \& Trullenque

Elaboración propia

8 Tom Cannon, La responsabilidad de la empresa. Respuesta a los nuevos retos sociales, económicos, éticos y de medio ambiente (Barcelona: Cannon Editores, 1994), 474-476. 
Como hecho digno de mención, se advierte que estos investigadores toman fechas exactas basadas en hechos o acontecimientos reconocidos de orden empresarial, que marcan un momento en la historia y que cuentan con características propias que determinan ciertas etapas o fases a manera de evolución de un fenómeno.

Por otro lado, Garrigues $\&$ Trullenque ${ }^{9}$ asumen tres etapas, con una postura mucho más concreta, a las que han denominado:

FIGURA $N^{\circ}$ 2. TRES ETAPAS DE LA RSE SEGÚN CARRGUES \& TRULLENQUE

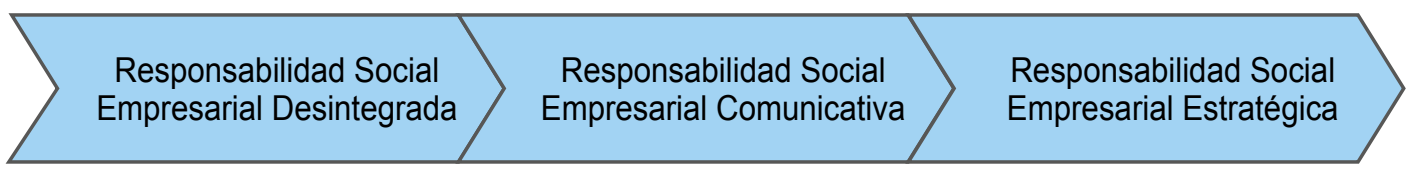

Fuente: Garrigues \& Trullenque

Elaboración propia

Como venimos analizando y dependiendo del enfoque y del ámbito desde donde observe el investigador, se emitirá un juicio diferente en cada una de estas etapas.

Por otro lado, tenemos a Corres ${ }^{10}$ (2004) quien propone cuatro fases, todas delimitadas por la regulación y la voluntariedad de la Responsabilidad Social Empresarial:

FIGURA Nº 3. FASES DE LA RSE SEGÚN CORRES

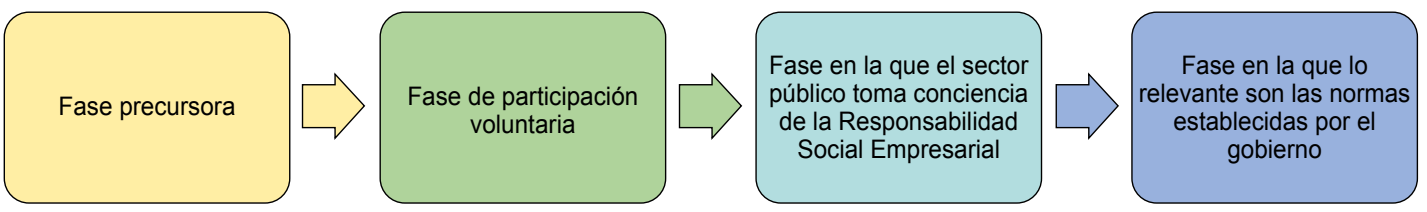

Elaboración propia

En una perspectiva diferente, Ramiro ${ }^{11}$ no precisa etapas, sino que basa su propia teoría en fechas concretas como, por ejemplo, el año 1976, en el que se publican las directrices de la Organización para la Cooperación y el Desarrollo Económico (OCDE) para empresas

9 Antonio Garrigues y Francisco Trullenque, “Responsabilidad social corporativa: ¿papel mojado o necesidad estratégica?”, Harvard Deusto Business Review, n. ${ }^{\circ} 164$ (2008): 164.

10 Pedro Corres, "Regulación y voluntariedad en la RSC", en Responsabilidad social corporativa, ed. por De la Cuesta, M. \& Rodríguez, L. (2004), 119-131.

11 Pedro Ramiro, "Las multinacionales y la responsabilidad social corporativa: de la ética a la rentabilidad, en El negocio de la responsabilidad. Critica de la responsabilidad social corporativa de las empresas transnacionales, ed. por Hernández, J. \& Ramiro, P. (Barcelona: Icaria, 2009), 47-78. 
multinacionales, o la manera como en 1995 la empresa Shell es denunciada por su impacto ecológico y social en Nigeria.

De todos los investigadores analizados, quienes pueden materializar una visión más aglutinadora son Araque \& Montero, ${ }^{12}$ quienes optan por etapas separadas por décadas, lo que permite una visualización exacta de los procesos por los que ha transcurrido la Responsabilidad Social Empresarial, y en la cual se tienen en cuenta además aspectos relacionados con la ética, la investigación, el desarrollo conceptual o la injerencia de los directivos.

TABLA N¹. EVOLUCIÓN HISTÓRICA DE LA RESPONSABILIDAD SOCIAL EMPRESARIAL

\begin{tabular}{|l|l|}
\hline \multicolumn{1}{|c|}{ Etapa } & \multicolumn{1}{|c|}{$\begin{array}{c}\text { Planteamiento ante el concepto de Responsabilidad Social } \\
\text { Empresarial }\end{array}$} \\
\hline Siglo XVIII - principios del XIX & Paternalismo de los grandes empresarios \\
\hline Siglo XIX - principios del XX & $\begin{array}{l}\text { Acciones sociales en respuesta al temor a nuevas } \\
\text { regulaciones }\end{array}$ \\
\hline Década de $1930-1940$ & $\begin{array}{l}\text { Equilibrio de intereses diversos a través de la nueva figura } \\
\text { del directivo }\end{array}$ \\
\hline Década de 1950 & Desarrollo conceptual \\
\hline Década de 1960 & Intensificación de posturas enfrentadas \\
\hline Década de 1970 & Perfeccionamiento del concepto de responsabilidad social \\
\hline Década de 1980 & Expansión de la investigación práctica \\
\hline Década de $1990-$ principios del XXI & $\begin{array}{l}\text { Nuevos temas de interés: business ethics o teoría de los } \\
\text { stakeholders, entre otros }\end{array}$ \\
\hline
\end{tabular}

Fuente: Araque \& Montero, 2006, p. 23.

Vemos que existen diversos criterios para definir las etapas de la evolución de la RSE. Los autores no proponen un criterio único de marcar dichas etapas, pero observamos que a lo largo de la historia existe información y documentos que verifican acciones que las empresas realizaban en beneficio de sus trabajadores.

El nacimiento de la ONU y posteriormente el surgimiento de los Derechos Humanos sirvieron como una base sólida para que se generara una mayor conciencia social por parte de los empresarios para con los actores de su entorno. Hechos como la Conferencia de Estocolmo en 1972, el Informe Brundtland en 1987 o el Protocolo de Kioto en 1997; la creación de grupos civiles como Amnistía Internacional, WWF, Greenpeace o Transparencia Internacional; las iniciativas formales empresariales como AA1000, SA8000, las Directrices de la OCDE o

12 José Montero Simó y Rafael Araque Padilla, La responsabilidad social de la empresa a debate (Barcelona: Icaria Editorial, 2006), 215-220. 
el mismo Pacto Mundial; así como el surgimiento de organizaciones como la Global Reporting Inititative o el Instituto Ethos, son todos acontecimientos que han servido como bloques para levantar esta construcción social y medioambiental conocida como RSE. Reconocemos que para la toma de conciencia sí contribuyeron estos organismos; no obstante, no todos incluyeron en sus políticas el verdadero objetivo de la RSE, sino que en cada realidad nacional se intoxicaron con la defensa de intereses particulares, desvirtuando su principal objetivo que era el de la toma de conciencia.

Según la Organización Internacional del Trabajo, en varios países europeos se ha impulsado muy activamente la RSE. Por poner un ejemplo, en el año 2000, el Gobierno del Reino Unido nombró un Ministro de Responsabilidad Social de la Empresa; en 2001, al promulgar la ley sobre la nueva regulación económica, Francia pasó a ser el primer país en obligar a las empresas cotizadas en la bolsa a presentar un balance triple (financiero, medioambiental y social); y en 2002, el Parlamento belga aprobó una ley para promover la producción socialmente responsable a través de la instauración de una etiqueta social voluntaria. ${ }^{13}$

La evolución de la RSE continúa hoy en día, la vemos enmarcada en la globalización, el nuevo poder de los stakeholders, la importancia de la ética en las organizaciones, el desarrollo de las tecnologías de la información y comunicación, el cambio climático y problemas ambientales globales y en un sinnúmero de factores que hacen que en la actualidad la RSE esté en constante mejora. La RSE está influenciada por factores de gran importancia, que no solo están afectando a las empresas, a las organizaciones, o a los medios, sino que involucran a la sociedad misma al acentuarse la crisis económica que viven determinadas poblaciones locales y comunidades. Entendemos que estos factores pueden ser variados, como la ética, la crisis económica, las comunicaciones, la prensa, actores con intereses políticos, elementos que están influyendo constantemente en el desarrollo de la RSE, pues están íntimamente relacionados.

Debemos precisar que los valores fundamentales que sostiene la RSE se encuentran ligados a temas como inversión social comunitaria, derechos humanos, mercado, índice de desarrollo humano, lugar de trabajo, ética y valores, medio ambiente y seguridad laboral. Se sabe que es un aspecto de la gestión que ha dejado de pertenecer solo a las organizaciones transnacionales y grandes empresas, debido a que ahora se está extendiendo a todo tipo de empresas de alcance nacional, regional y local. A pesar de que sabemos que esto es así, nos damos cuenta de que la gran mayoría de las empresas vienen desarrollando una deficiente gestión en RSE o aún no han desarrollado una estrategia clara para los programas a implementarse en sus organizaciones. Se trata de una gestión que no ha sido valorada por los directivos de las organi-

13 OIT, "Promulgación de Ley para la producción socialmente responsable a través de la instauración de una etiqueta voluntaria”, acceso el 15 de marzo de 2018, http://white.oit.org.pe/estad/laclispub/ndestacados/SOCIAL.pdf 
zaciones, pues se desarrollan programas sociales que nada tienen que ver con la problemática de la comunidad o población y se realizan por cumplir, ¿o se trata de que a pesar de haber desarrollado diversas estrategias, no es suficiente o peor aún, haber desarrollado una gestión social eficiente y que no es suficiente para los actores del entorno?

Partimos de la premisa de que toda organización debe ser consciente de que sus acciones tienen repercusiones en la población de su área de influencia en la que se desarrolla. Los pobladores donde están ubicadas las empresas, pueden sufrir tanto externalidades negativas (impacto paisajístico, fluctuaciones en el valor del suelo, escasez de agua, poluciones, etc.) como positivas (mejoras en las vías de comunicación, aumento de la renta disponible, consumo de bienes y servicios locales, desarrollo económico local, etc.). Toda empresa, dentro de su Política Organizacional, sabe que sus actividades pueden generar impacto en su entorno; esto lo conoce desde que aparece la idea de negocio y al levantar la línea base socioeconómica y ambiental, determina estos impactos y con base en ellos plantea su plan de manejo para minimizar, eliminar o compensar los negativos y potenciar los positivos. Este compromiso planteado con su entorno social directo crea vínculos muy estrechos entre la empresa y la comunidad de la cual forma parte, que repercutirán positivamente en la organización tanto por la identificación y compromiso de los miembros de esa comunidad que la empresa incorpore como trabajadores, como por la especial atención que cabe esperar le brinden las administraciones que representan a la misma.

La RSE ha cobrado mucha fuerza, pero su implementación no ha sido del todo eficiente, pues se denota una falta de participación e involucramiento de los actores que intervienen y se ha venido realizando de forma inadecuada bajo otros términos basados en la presión de la población, intereses individuales políticos, interés por la conciencia ecológica disfrazada, etc. Esto ha ocasionado que las empresas se desvíen del objeto de su negocio para dedicarse a cumplir exigencias normativas y de la sociedad.

Toda esta realidad amerita una reflexión desde diferentes puntos de vista en torno a la actividad empresarial. Este modelo de gestión incluye un conjunto de responsabilidades de carácter social, económico, cultural y ambiental que deben tener las organizaciones e instituciones con los actores de su entorno, manteniendo el criterio de la sostenibilidad como principal indicador de desempeño, con aplicación de políticas, planes, programas y buenas practicas que implican una mayor transparencia de la gestión organizacional, sin dejar de lado los intereses de los actores involucrados con el objetivo de la organización.

En el Perú existen empresas y organizaciones que, a partir de políticas de RSE y gracias a su libre participación en el mercado, desarrollan diferentes tipos de programas y hasta en algunos casos reemplazan funciones del Estado. Existen empresas mineras formales que desarrollan programas sociales que son supervisados por el Ministerio de Energía y Minas, tanto 
su cumplimiento como los montos de inversión, y así también los programas sociales que son aprobados al amparo de un instrumento de gestión ambiental.

Entonces, ¿por qué estas empresas desarrollan programas sociales con las comunidades y poblaciones de su entorno sin estar obligadas a hacerlo?

Tenemos que, históricamente, la empresa capitalista nació como una organización cuya función social era la acumulación de capital. En el contexto de la primera revolución industrial, el empresario capitalista reinvertía la mayor parte del excedente generado y llevaba a cabo su función social, la acumulación de capital, a partir de su búsqueda del beneficio económico. Fue recién en tiempos modernos, y cuando el nivel de acumulación era suficiente, que los dueños de las empresas se unieron a la labor filantrópica ya existente hasta ese momento en manos de particulares. Es así que a fines del siglo XIX se desarrolló una filosofía empresarial que reconocía que la empresa se asentaba en una comunidad determinada y que por lo tanto se debía a ella. ${ }^{14}$

Según Baltazar Caravedo Molinari, el vínculo de una organización con su medio se divide en tres categorías: el paternalista o filantrópico, un tipo de trato que efectúa donaciones a asociaciones con el objeto de realizar obras de caridad y asistencia; el inversionista social, que posee una visión de mediano plazo e invierte con predominio en proyectos que generan beneficios para la empresa y la comunidad; el socialmente responsable, que se caracteriza por su enfoque de largo alcance del lugar y que comparte con otros actores locales. Destina recursos a proyectos sostenibles e invierte en sus trabajadores para mejorar su rendimiento, identidad y prestigio. ${ }^{15}$

Así nació la RSE, entendida como un comportamiento voluntario por parte de los funcionarios de las empresas, para contar con un buen escenario social, económico y ambiental del entorno en el cual ejercen sus actividades, participar con la población de su área de influencia y sobre todo ganarse una identidad corporativa, imagen y paz social. Como comenta Pedro Franco, la empresa privada peruana se ha preocupado más por las cuestiones sociales que se derivan de su actuación dentro del entorno en que se desenvuelven. De esta manera, el aporte en materia de RSE de las empresas ha tomado diversos aspectos tales como las donaciones, los aportes monetarios, los beneficios brindados a la comunidad (salud, educación, medio ambiente) y otras actividades como son el fomento de las actividades recreativas, científicas, tecnológicas, e incluso, la promoción y apoyo al desarrollo de microempresas. ${ }^{16}$

14 Garavito, “Desarrollo de una filosofía empresarial”, acceso el 15 de julio de 2017, http://www.pucp.edu.pe/economia/ pdf/DDD258.pdf

15 Wilfredo Pérez Ruiz, "Responsabilidad Social en el Perú", blog personal, acceso el 8 de abril de 2012, http://wperezruiz. blogspot.com/2012/03/la-responsabilidad-social-en-el-peru.html.

16 Pedro Franco Concha, Diagnóstico de la responsabilidad social en el Perú (Lima: Centro de Investigación de la Universidad del Pacífico, 2007), 50. 
El sector privado muestra una serie de características que permiten conocer en qué medida la RSE se ha incorporado en las organizaciones. Así tenemos que los sectores económicos peruanos más relacionados al tema de la RSE son el minero y el energético. Las actividades del sector extractivo implican el uso de los recursos naturales del país y a la vez exigen que realicen un manejo adecuado de los mismos para evitar daños al medio ambiente. Muchas empresas mineras han adoptado planes y programas de responsabilidad social internos y externos que se ven reflejados en los denominados Balance Social o Planes de Relaciones Comunitarias en los cuales se busca informar a sus stakeholders sobre la marcha de sus actividades y el impacto en su entorno.

Las empresas vinculadas con estos sectores son diferentes, pues se enfrentan a una serie de disposiciones legales que tienen que ver con una RSE "obligatoria” por estar contemplada en una norma jurídica, convenio de titularidad de terreno superficial, consumo de bienes y servicios locales, desarrollo local, plan de relaciones comunitarias e instrumentos de gestión ambiental que incluye el aspecto social, entre otros, pero la diferencia radica en la idiosincrasia de la población con la que lidian estos temas. Las empresas extractivas se caracterizan por tener un diseńo estructural que sirve de base para su funcionamiento, no funcionan al azar ni tienen éxito en forma aleatoria, sus rentas o ganancias están ligadas a la explotación de recursos naturales, por los cuales deben pagar una serie de impuestos y desarrollar una sinfín de estudios para encontrar los recursos y que su explotación sea rentable. Dentro de este contexto, las organizaciones deben ser administradas y los ejecutivos que las dirigen o administran deben conocer a fondo la problemática social. Podemos señalar sin temor a equivocarnos que el éxito o el fracaso de la mayoría de las organizaciones extractivas depende del factor social; por ello, se trabaja mucho antes de poner en práctica un proyecto de inversión, para lo cual se requiere tener la habilidad para saber tratar con personas que tienen distintas personalidades y lograr relacionarse y comunicarse con ellas. También podemos mencionar que no existe la fórmula perfecta para lidiar con esta problemática, pues cada sociedad, población o comunidad es diferente, sus intereses son desiguales, los actores son distintos y las economías disparejas. Esto no tiene que ver con los conocimientos técnicos o especializados de cada ejecutivo o grupo de profesionales, sino con el desarrollo de habilidades para las relaciones interpersonales y con el conocimiento de la verdadera problemática de cada sociedad.

Los peruanos, tanto autoridades como ciudadanos, seguimos aprendiendo sobre la importancia de conservar el entorno y evitar conflictos socioambientales en torno a la actividad extractiva que tanto beneficio trae a nuestra nación. Aunque son muchas las cosas que aún deben ser mejoradas, creemos que la principal y el punto de partida por parte del Estado es mejorar su gestión ambiental, que involucra la promulgación de normas legales que fomenten actividades de prevención de la contaminación y la creación de una administración pública ambiental ordenada, esto con la finalidad de evitar la descoordinación y los conflictos de com- 
petencia entre las autoridades que intervienen en la aprobación de proyectos que no hacen más que entorpecer y demorar la aprobación de las certificaciones ambientales pertinentes.

Cada uno de estos aspectos guarda relación directa, por ejemplo, la evaluación ambiental previa. De su existencia depende la eficacia del Sistema Nacional de Evaluación del Impacto Ambiental, la cual se viene tratando de mejorar. Solamente con una real política ambiental, con una ordenada organización administrativa y con normas legales idóneas podremos contar con un proceso de evaluación ambiental previa eficiente. Si no alcanzamos estos lineamientos, no podremos contener la generación de conflictos internos y externos que obstaculizan la inversión privada y el desarrollo local y regional del país.

Es importante señalar que la legislación ambiental nacional se caracteriza por ser controladora y punitiva. Hace falta evolucionar a una legislación ambiental promotora de la prevención ambiental y que vaya acorde con la dinámica de la actividad minera, pues las condiciones son cambiantes y debemos evitar que las certificaciones ambientales, licencias, autorizaciones y permisos caigan en la desactualización o peor aún en incumplimientos. No solo con instrumentos de gestión ambiental, cumplimiento de la norma, la implementación de una cultura organizacional y la imposición de sanciones severas se consigue la protección del ambiente y con ella las buenas relaciones con los actores del entorno empresarial, ni con la imposición de sanciones y amenazas se logra que un trabajador, técnico u operario desarrolle eficientemente un trabajo, pues se necesita de un marco legal coherente, políticas claras y precisas y que los términos de referencia sean de fácil entendimiento para su cumplimiento. Solo con una legislación y reglas claras se puede fomentar una cultura organizacional eficiente y por ende la tan anhelada responsabilidad social empresarial que nuestro país necesita.

Actualmente existe una preocupación constante sobre la relación entre el hombre (actividad económica o negocio) y la naturaleza (su entorno que involucra a las poblaciones y su medio ambiente). Las cuestiones sobre la dinámica de la población han estado muchas veces en el debate y han sido abordadas por numerosas disciplinas. La relación entre población y medio ambiente ha sido una preocupación casi permanente para las sociedades, pero es evidente que en las últimas tres décadas se ha puesto una atención muy particular por el peligroso desequilibrio producido a causa de las actividades humanas en las regiones más fértiles y útiles para la obtención de los recursos naturales que los hombres necesitan para vivir. ${ }^{17}$

La problemática ambiental contemporánea deriva de una concepción "holística" (todo incluido) que se refiere al ambiente natural como un régimen en el cual sus diversos integrantes (bióticos y abióticos) generan en conjunto algo más que la simple suma de sus partes (sinergia).

17 UNRC, "La población y el medio ambiente, América Latina - Nuestra Región”, acceso el 27 de enero de 2019, https:// www.unrc.edu.ar/publicar/19/dosier5.htm 
Se percibe, asimismo, la existencia de una relación entre la actividad humana (en este caso una actividad empresarial minera) y la problemática socioambiental (relaciones con los stakeholders y la certificación ambiental) que genera obligaciones y responsabilidades para el titular. El problema ambiental es una consecuencia, deseada o no, de las actividades económicas desarrolladas por el hombre, por eso, resulta necesario regularlo de manera eficiente. Por ello, es imprescindible identificar las fuentes o causas de los riesgos medioambientales verdaderos, analizarlos de manera científica y no como resultado de las percepciones de unos cuantos. Los impactos que generan o podrían generar las actividades económicas desarrolladas por el hombre deben contar con todos los estudios que permitan adecuar al titular de una actividad económica de forma adecuada para mitigar o disminuir los impactos negativos y por ende lograr los objetivos de cuidado y protección ambiental.

Se deben regular los problemas empresariales considerando una actuación ambiental, vinculados a criterios éticos y políticos para identificar y evaluar los aspectos ambientales y sus posibles riesgos. Asimismo, es necesario referirse a procedimientos técnicos y de costo-beneficio que se deben tener en cuenta al momento de elegir o decidir por las distintas opciones e instrumentos de gestión ambiental, pues todo proceso económico productivo alcanza su mayor énfasis cuando nos referimos al derecho que tenemos las personas a un ambiente sano y adecuado y en la denominación de una adecuada política ambiental y esto se vuelve más intenso con respecto a la selección de los instrumentos de gestión ambiental y su aplicación. En este escenario aparece el Derecho interrelacionado fuertemente con el conocimiento científico, que le brinda la base para muchas de las decisiones críticas que deben tomarse en torno a la protección ambiental y a los alcances de RSE, sin caer en la función pública que es tarea exclusiva del Estado.

Como hemos analizado, la RSE está relacionada a toda clase de empresas y sectores, pero la encontramos más desarrollada en los sectores extractivos. La RSE que ejecuta el titular minero no solo debe estar relacionada a proyectos de desarrollo social y ambiental en la comunidad de impacto directo o indirecto tal como lo enfoca la gestión de relaciones comunitarias, sino también en función a las estrategias de desarrollo y valor compartido hacia sus grupos de interés (stakeholders), sean estos internos o externos.

En el caso de las industrias extractivas, los cambios que han experimentado a raíz de la adopción del tema de RSE ha sido la forma de replantear sus estrategias de comunicación con las comunidades existentes en sus áreas de influencia e invertir en los pobladores de estas comunidades para que ellos mismos puedan alcanzar el desarrollo sostenible más allá de la ayuda que le pueda prestar la empresa; no obstante, se encuentra en la lucha de mejorar la percepción de la población y mientras tanto los conflictos sociales siguen, y cada día vemos más proyectos mineros paralizados o bajo la sombra de una población, que lejos de valorar los programas sociales implementados, se deja llevar por actores negativos que utilizan las 
masas para satisfacer sus intereses individuales, los cuales se encuentran bien disfrazados con la preocupación por el medio ambiente.

Debemos promover y fortalecer la cultura de RSE a través de las normas y de la ética empresarial como una forma de atender a la pobreza del país, sin desvirtuar la función pública del Estado peruano, impulsando que la RSE se desarrolle teniendo en cuenta la sostenibilidad social, económica y ambiental. García incluye en su tesis la visión de impulsar con entusiasmo, conciencia y alineamiento en la organización y hacer de la empresa un ente más responsable y sostenible. Claro está que si no existe un compromiso firme, no se tendrá efectos positivos para la obtención de resultados, por lo que se hace necesario tomar acciones concretas y resultados efectivos (García, 2015). ${ }^{18}$

\subsection{Dimensiones de la responsabilidad social empresarial}

La responsabilidad social de la empresa tiene dos dimensiones:

- Una dimensión interna, que afecta a sus trabajadores, a su impacto ambiental, a la gestión de los recursos, a sus condiciones de trabajo o a la peligrosidad de sus productos.

- Una dimensión externa, que se da frente a la sociedad en su conjunto, proveedores, consumidores, clientes, contratistas, dicho en otras palabras, los denominados stakeholders o partes interesadas que son los colectivos con los cuales la empresa se relaciona y a los que debe generar algún valor si se autodefine como socialmente responsable.

Sea cual sea la dimensión en la que participe, todos los grupos de interés tienen necesidades comunes, que son:

- Transparencia informativa: especialmente valorada por quienes desean conocer en todo momento determinados aspectos esenciales e impacto presente y futuro de la organización.

- Participación: la comunicación permanente, transparencia y el diálogo resultan imprescindibles cuando se quiere establecer una relación de beneficio mutuo y se desea conocer las necesidades de las partes interesadas.

- Beneficio mutuo: las personas y grupos sociales que interactúan con las empresas esperan obtener contraprestaciones que les permitan desarrollarse y progresar no solo en lo económico, sino también en lo social y en el cuidado del medio ambiente de forma sostenible, con vocación de largo plazo y sin comprometer el desarrollo de las generaciones futuras.

18 Fabiola Lizzet, García Paredes, "La responsabilidad social en el sector minero y su incidencia en el manejo de los conflictos socioambientales en el Perú 2005-2013”, acceso el 19 de noviembre del 2017, http://dspace.unitru.edu.pe/handle/ UNITRU/995 


\subsubsection{Dimensión interna}

FIGURA N ${ }^{\circ}$. DIMENSIONES INTERNAS RSE

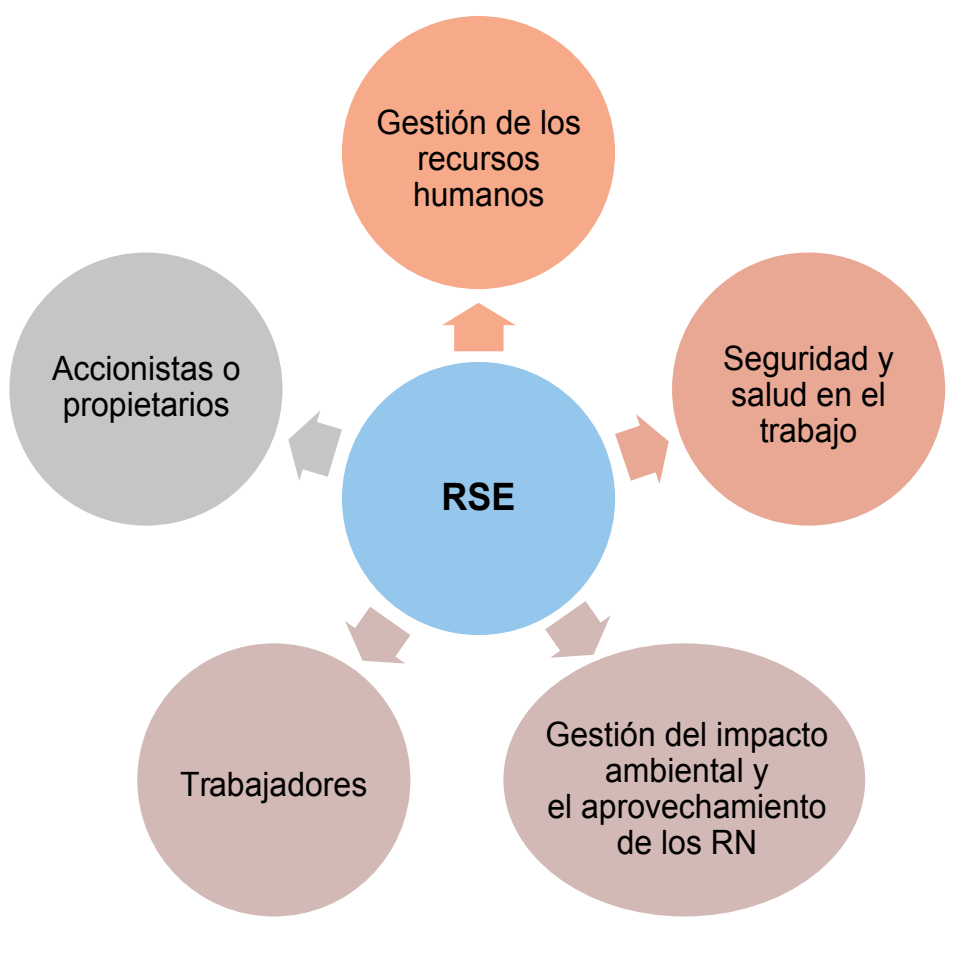

Elaboración propia

\section{Gestión de los recursos humanos}

Uno de los desafíos más importantes a los que se enfrentan hoy en día las empresas es atraer a trabajadores calificados y lograr su permanencia en la organización. En este contexto, las medidas podrían incluir la formación continua; la mejora de la información en la empresa; un mayor equilibrio entre trabajo, familia; una mayor diversidad de recursos humanos; la igualdad de retribución y de perspectivas profesionales para las mujeres; la participación en los beneficios o en el accionariado de la empresa y la consideración de la capacidad de inserción profesional y la seguridad en el lugar de trabajo.

\section{Seguridad y salud en el trabajo}

El aumento en la tendencia a subcontratar a empresas contratistas mineras y de actividades conexas hace que las empresas dependan en mayor medida del comportamiento de sus contratistas en el ámbito de la salud y la seguridad, sobre todo cuando trabajan en las 
instalaciones de la empresa o en la Unidad Minera. Vivimos una etapa en la que las empresas incluyen en sus políticas organizacionales, criterios de salud, seguridad, vigilancia e higiene ocupacional en el puesto de trabajo, incluso implementar estándares internacionales como son las normas OHSAS e ISO las cuales hacen que sus requisitos sean uniformes y deben cumplirse. La tendencia es clara y los esfuerzos por mejorar la salud y la seguridad en el lugar de trabajo se multiplican, por un lado, por las presiones de carácter regulatorio y, por otro, por la imagen de la organización.

\section{Gestión del impacto ambiental y el aprovechamiento de los recursos naturales}

En general, la disminución del consumo de recursos naturales, el manejo integral de residuos y la minimización de emisiones contaminantes aumentan la competitividad y reducen el impacto al medio ambiente. Por otro lado, la Política de Gestión Integrada de la organización mejora su imagen corporativa. La RSE incentiva la realización de ecoauditoría y ecogestión para estimular la mejora constante de buenas prácticas ambientales los cuales posteriormente son verificados por organismos supervisores.

\section{Trabajadores}

Incluye a todas aquellas personas que desarrollan su trabajo en la organización con un contrato, laboral o profesional, y a cambio de una retribución económica. El término trabajador es lo suficientemente genérico como para abarcar tanto a los empleados directos como a aquellos otros cuya relación contractual la mantienen con una empresa empleadora intermediaria (subcontratas o empresas de trabajo temporal). Mientras que los trabajadores o profesionales que facturan sus servicios a la empresa se encuadran en el grupo de interés de los proveedores. Los empleados se encuentran habitualmente representados por los supervisores, comités de empresa y/o los sindicatos de trabajadores. Precisan de una retribución justa, salud y seguridad, respeto y desarrollo profesional en igualdad de condiciones, mantenimiento del empleo, conciliación de la vida familiar, etc.

\section{Accionistas o propietarios}

Son todas aquellas personas y entidades que poseen participaciones en la empresa. El accionista o propietario con vocación de permanencia en la organización se acerca al concepto de propiedad o empresario, normalmente involucrado en la gestión y en la marcha del negocio. El accionista que busca exclusivamente una rentabilidad económica a su aportación es asociado con la figura del inversor externo, individual o institucional, por lo que puede ser más adecuado incluirlo como grupo de interés externo. 


\subsubsection{Dimensión externa}

La responsabilidad social también se extiende hasta las comunidades locales e incluye a otro grupo de interlocutores y actores.

\section{FIGURA N ${ }^{\circ}$. DIMENSIONES INTERNAS RSE}

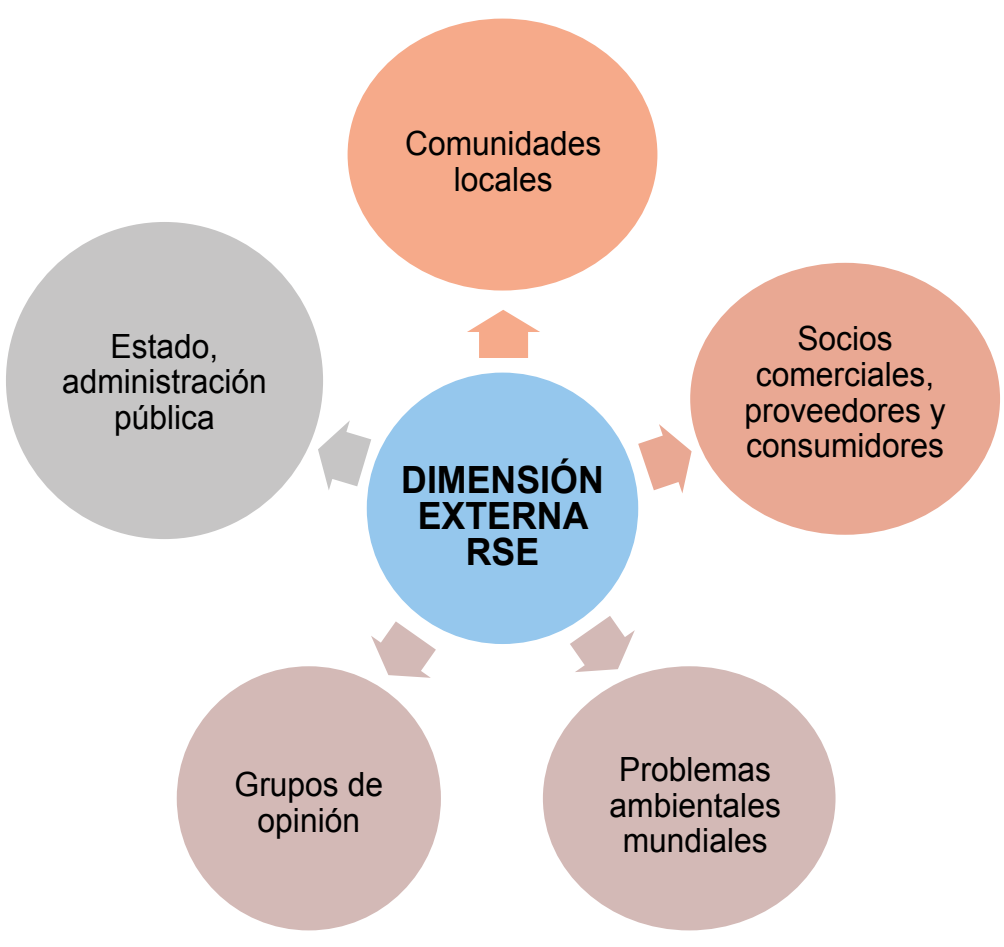

Elaboración propia

\section{Comunidades locales}

La responsabilidad social de las empresas abarca también la integración de las empresas en su entorno local. Estas contribuyen al desarrollo de las comunidades en que se insertan, sobre todo de las comunidades locales, proporcionando puestos de trabajo, salarios y prestaciones, e ingresos fiscales. Por otro lado, las empresas dependen de la salud, la estabilidad y la prosperidad de las comunidades donde operan. Así, por ejemplo, dado que la mayor parte de sus contrataciones tienen lugar en el mercado local, estarán interesadas en que en su lugar de ubicación haya personas con las competencias que requieran.

Las empresas interactúan con el entorno físico local. Precisan de un entorno adecuado para su producción y su oferta de servicios: unas adecuadas redes de comunicación, un medio 
ambiente limpio. Por otro lado, las empresas pueden ser responsables de diversas actividades contaminantes: polución acústica, lumínica y de las aguas; contaminación del aire, del suelo y problemas ecológicos relacionados con el transporte y la eliminación de residuos.

El establecimiento de relaciones positivas con la comunidad local (por ejemplo, la colaboración con organizaciones de defensa del medio ambiente, el ofrecimiento de servicios de guardería a sus trabajadores o el patrocinio de actividades deportivas o culturales) y la consiguiente acumulación de "capital social" es especialmente interesante.

\section{Socios comerciales, proveedores y consumidores}

Las grandes empresas son al mismo tiempo socios comerciales de las empresas más pequeñas, ya sea en calidad de clientes, proveedores, subcontratistas o competidores. Las empresas deben ser conscientes de que sus resultados sociales pueden verse afectados por las prácticas de sus socios y proveedores a lo largo de toda la cadena de producción.

Los efectos de las medidas de RSE no se limitarán a esta, sino que afectarán también a sus socios económicos. En particular, este es el caso de las grandes empresas que han subcontratado una parte de su producción o servicios y que, por lo tanto, pueden haber asumido una responsabilidad social suplementaria por lo que respecta a dichos proveedores y a su personal, teniendo en cuenta que, en ocasiones, el bienestar económico de los proveedores depende mayoritariamente o totalmente de una única gran empresa.

\section{Problemas ambientales mundiales}

Debido al carácter global y efecto transfronterizo de muchos problemas medioambientales relacionados con las empresas y a su consumo global de recursos, las empresas son también actores en el medio ambiente mundial. Por ejemplo, en la emisión de gases de efecto invernadero o la contaminación de los mares, localizada en puntos concretos, pero que se dispersa por todo el planeta. Por ello, pueden tratar de obrar con arreglo a su responsabilidad social tanto a nivel nacional como internacional, pueden también fomentar la reducción del impacto ambiental de sus actividades a lo largo de su cadena de producción y hacer mayor uso de herramientas internacionales vinculadas a la gestión y a los productos.

Grupos de opinión, administraciones públicas, comunidades locales y sociedad y público en general

Si recapacitamos sobre las necesidades y expectativas de los grupos de interés, todos ellos tienen tres necesidades genéricas básicas:

- Transparencia y confianza, especialmente valoradas por quienes desean conocer en todo momento determinados aspectos esenciales e impactos que genere la organización. 
- Participación, la comunicación permanente y el diálogo resultan imprescindibles cuando se quiere establecer una relación de beneficio mutuo y se desea conocer las necesidades de las partes interesadas.

- Beneficio mutuo, las personas y grupos sociales que interactúan con las empresas esperan obtener contraprestaciones que les permitan desarrollarse y progresar no solo en lo económico, sino también en lo social y en lo medioambiental de forma equilibrada con vocación de largo plazo y sin comprometer el desarrollo de las generaciones futuras.

\subsection{Actores involucrados en la RSE}

En esta parte se recoge el papel que juegan, o deberían jugar, diferentes actores implicados en el desarrollo de la RSE. Se debe señalar que, para una adecuada introducción de la RSC en la sociedad, se precisa el apoyo de:

- Instituciones:

- Administración (central, regional, local).

- Universidad (docencia e investigación).

- Sindicatos.

- Entidades privadas:

- Asociaciones profesionales, empresariales y científicas.

- Las ONG.

- Asociaciones de consumidores,

- Medios de comunicación:

- Prensa especializada.

- Canales de masas.

\subsubsection{Instituciones}

\section{Administración pública}

Veamos cómo puede colaborar la Administración Pública:

- Contribuyendo a la dinamización del mercado local contemplando criterios de RSE en la gestión de sus propias inversiones financieras. 
- Jugando un papel regulador, facilitador y promotor en el desarrollo de una normativa que exija transparencia a las entidades gestoras de fondos de inversión y programas sociales, indicando si incorporan o no criterios sociales, de buen gobierno y ambientales.

- Estimulando la inversión socialmente responsable, estableciendo políticas públicas favorables y verificables, de forma que se incentive la inversión en sectores como, por ejemplo, energías renovables, reducción de la deforestación.

\section{Universidades / Centros de investigación}

Las universidades están prácticamente ausentes en el debate sobre la RSE, investigaciones a nivel de diagnóstico, pero no de aplicación de mejoras o implementación de modelos exitosos. Hay publicaciones superficiales, no hay artículos serios o investigaciones que sean algo más que una respuesta apresurada a la circunstancia coyuntural de cada momento.

No están presentes en la medida en que deberían estar en este debate, como una organización de intermediación, que jueguen un papel entre gobiernos y empresas creando materiales, fomentando espacios de encuentro, facilitando proyectos comunes que lubrican un poco esta relación siempre difícil entre gobierno y empresa.

\section{Sindicatos}

Las organizaciones sindicales han ocupado siempre un lugar explícito en el discurso teórico y político sobre la RSE, al lado de otros grupos de interés, cuyas perspectivas y preocupaciones ha de asumir la empresa responsable. La RSE debe ser complementaria y de ninguna manera sustitutoria de la legislación referente a los derechos sociales y medioambientales y a las normas fijadas por la negociación colectiva, lo que implica que cualquier empresa que no respete los convenios, la legislación o el diálogo social no podrá ser definida como socialmente responsable, subrayando la necesaria promoción de la negociación colectiva donde esta no exista o sea débil.

\subsubsection{Entidades privadas}

\section{PYMES, grandes empresas y agrupaciones empresariales}

Las pequeńas y medianas empresas son las grandes olvidadas en la discusión y la implementación de la RSE. Que ha tenido como gran protagonista a la empresa multinacional o a la gran corporación. No es fácil fomentar el tema en las pymes por el tema de costos, porque la responsabilidad social, nos guste o no nos guste, representa un costo para las empresas. Que después se pueda convertir ese coste en una mayor facturación, en una mayor penetración, sí, pero no es fácil su visualización para un pequeño empresario. 
Las pymes, muchas veces, cumplen o desarrollan compromisos de responsabilidad con el entorno donde desarrollan su actividad, con las comunidades locales, y se trata también de poner esto en valor en el mercado, al menos mediante el conocimiento de lo que se está haciendo. No se trataría, pues, de hacer cosas nuevas, sino de añadir valor social o medioambiental a prácticas preexistentes. Han mostrado cómo se puede ser responsable con un entorno provocando crecimiento en el país y arrastrando a toda la economía en crecimiento.

\section{ONG. La sociedad civil organizada}

Un Estado ausente, la pérdida de capacidad de los gobiernos para regular en una economía global, la proliferación de las subcontratas y el creciente interés de los ciudadanos por las vulneraciones sociales y medioambientales han incrementado la importancia de la labor de las organizaciones sin ánimo de lucro. Los ciudadanos tenemos la obligación de promover, garantizar e incentivar a las empresas a que desarrollen prácticas comerciales responsables. Sin embargo, todavía no nos ponemos de acuerdo sobre la importancia de la opinión pública y de las decisiones de consumo.

\section{Consumidores / inversores}

Se trata de otros de los grupos de interés clásicos que se pueden encontrar mencionados en cualquier texto político o académico sobre la RSE. La RSE debe avanzar en sintonía con la sociedad, y para ello debe contar con la colaboración y el apoyo de los principales agentes, desde el Estado hasta los consumidores, pasando por las empresas, los sindicatos y los creadores de opinión, la prensa, las universidades. Se espera que contribuyan a través de la selección positiva y negativa que se lleva a cabo con las decisiones de consumo o inversión, a la extensión y maduración de la RSE e influir en la administración pública.

Lo que ocurre es que esta teórica capacidad de influencia y determinación que se adjudica a este grupo de interés queda puesta entre paréntesis si se atiende a algunas consideraciones y algunos datos planteados desde el sector privado sobre la formación, información y motivaciones de los consumidores.

\subsubsection{Medios de comunicación}

Respecto al papel de los medios de comunicación en relación a la RSE, la opinión pública representa uno de los motores del desarrollo de la RSE, pues las implicaciones para el sector son más grandes y más delicadas que para el resto de las empresas: tienen ante sí la posibilidad y la capacidad de movilizar la opinión de los ciudadanos en torno a estas cuestiones. 


\subsection{Políticas públicas y RSE}

La RSE es un proceso que incluye necesariamente la gestión de la actividad empresarial en su relación con los grupos de interés tanto internos como externos. Un proceso de gestión que también comporta un nuevo modelo de gestión de las externalidades empresariales en lo económico, social y medioambiental. El establecimiento de los límites o fronteras dentro de los cuales estos costes y beneficios han de gestionarse es cuestión de política y estrategia empresariales, pero también afectan cada vez más a cuestiones de gobernanza.

Por otra parte, en la medida en que la RSE supone la aparición de nuevos retos y oportunidades que afectan al espacio público, se les plantea a los gobiernos la necesidad de definir una propuesta política en relación con estas cuestiones.

\section{PARADIGMA: ¿RENTABILIDAD Y/O RESPONSABILIDAD?}

El paradigma empresarial se evidencia cuando las empresas tienen que pensar en cómo actuar y relacionarse con sus stakeholders o grupos de interés, y a la vez seguir con los objetivos de su línea de negocio, todo dentro de un marco de responsabilidad social empresarial y rentabilidad. Debemos entender que la línea del negocio minero es lucrar con la explotación de los recursos naturales minerales. Surgen entonces las interrogantes. ¿Se puede ser rentable y éticamente responsable a la vez? ¿la empresa puede mantener una relación armoniosa con sus grupos de interés y al mismo tiempo ser rentable y obtener ganancias? ¿se puede hacer negocios sin dañar intereses de terceros?

En muchos casos, la respuesta es afirmativa, siempre y cuando se apliquen de manera eficiente los programas sociales que conforma la RSE de la organización. Ocurre que, a partir de una serie de esfuerzos y compromisos profesionales, las empresas socialmente responsables con marcos de actuación sostenidos en el respeto a sus stakeholders pueden mantener relaciones armoniosas con estos (licencia social) y no dejar de ser eficientes y obtener dividendos. Es por ello que se puede afirmar que obtener ganancia no será una situación que tenga que verse o entenderse distanciada de la posibilidad de entablar relaciones armoniosas con grupos de interés (como por ejemplo comunidades locales) con quienes se mantienen vínculos diversos, complementado y no afectando sus formas de vida.

En el Perú son varias las empresas mineras que siguen este tipo de pautas de actuación corporativa. Sin embargo, para estas, alcanzar ese equilibrio entre ser responsables y a la vez rentables no ha sido - ni es - una labor sencilla. Dicho proceso se ubica en un contexto complejo, caracterizado por ser una entremezcla de conflictividad social con avances en la aplicación de herramientas de gestión social. Ello significa que a la par de un crecimiento en la producción minera así como una proyección positiva de instalación de proyectos mineros a futuro cercano, acompañados de mejores prácticas de relacionamiento comunitario apren- 
didas en la dinámica del día a día, se presentan aún situaciones de conflictividad generados por una combinación de acuerdos incumplidos, expectativas poco posibles de ser alcanzadas, afectaciones a condiciones ambientales, discursos agitadores, vulneraciones de derechos, entre otros.

A pesar de las dificultades, no podemos negar que, en minería, hemos avanzado en materia de relacionamiento comunitario y capacidad de diálogo generando confianza en la población. Es un sector que sabe que, para poder establecer relaciones armoniosas con las poblaciones de su entorno y alcanzar negociaciones exitosas, es necesario dialogar para mostrar transparencia y confianza. El diálogo resulta la herramienta fundamental para reducir las posibilidades de conflicto, lo cual significa generar condiciones sociales para la viabilidad social del negocio.

Sin embargo, vemos que resulta aún insuficiente esta herramienta para establecer relaciones armoniosas. Ocurre que, de manera adicional a este contexto complejo, muchas veces para afianzar en minería buenas prácticas en la dinámica empresarial con los stakeholders, se ha visto como matiz del trabajo social que el discurso y la práctica de la RSE muestren resultados concretos y efectivos que estén alineados con la rentabilidad de la empresa. Es decir, alinear prácticas responsables con los tiempos exigidos por la rentabilidad. Es aquí donde se pueden encontrar los principales problemas al momento de poder alcanzar que el equilibrio, en el binomio presentado, se evidencie: las prácticas de responsabilidad, sobre todo las que significan relacionamiento con comunidades locales, no siempre se realizan en tiempos parecidos a los exigidos por la dinámica de la ganancia; esto hace ver a relaciones comunitarias, por ejemplo, como lentas en comparación con la necesidad de obtener beneficios económicos a corto plazo, a pesar de que una buena relación con los stakeholders, sostenida en el diálogo, garantiza la viabilidad social del proyecto.

Dentro de lo avanzado a la fecha en materia de relacionamiento comunitario, existe un conjunto de actividades relacionadas a generar justamente esas condiciones sociales para la viabilidad social de los proyectos de inversión minera, actividades sostenidas principalmente en un marco legal de gestión social y participación ciudadana que sumado a la complejidad de la actividad, lo incierto del negocio minero, la volatilidad de los precios de los metales en el mercado internacional y la incertidumbre política se tornan un tanto complicadas de implementar, pues para garantizar la viabilidad social y económica del proyecto dependemos de aspectos externos que pueden o no, en un determinado momento, afectar al negocio minero $y$, por ende, a todos los programas que de él se desprenden.

La vida de un proyecto minero coincide con la participación de la población para la viabilidad del negocio. En esta línea de tiempo encontramos aquellas actividades mediante las cuales la empresa busca tener acceso a aquellos terrenos superficiales donde se estaría realizando su actividad, sobre todo cuando el propietario es una comunidad campesina. Es decir, existen 
momentos complejos en esa interrelación empresa minera y comunidad campesina cuando la empresa tiene que acceder a terrenos que no son suyos para poder llevar a cabo su actividad de exploración y luego de explotación. Es importante que este momento sea positivo, pues de ese convenio dependerá la ejecución del proyecto minero, ya que toda la legislación minera está orientada a que el titular de la concesión minera se ponga de acuerdo con el titular del terreno superficial para poder desarrollarlo.

Nos detenemos en este momento específico donde el titular minero debe ponerse de acuerdo con el titular del terreno superficial y este es una Comunidad Campesina. ${ }^{19}$ De la manera cómo se realice la negociación alrededor del acceso a los terrenos comunales, pueden depender, por ejemplo, futuras negociaciones que se estarían realizando, así como dinámicas de buenas prácticas de convivencia y cotidianeidad. Es el momento en el que la empresa minera establece relaciones con las comunidades que significan posibles impactos sociales, por lo que es muy importante plantear la lógica de la RSE. Es necesario que las condiciones en las que se asienta este primer encuentro sean las adecuadas para conseguir la viabilidad del proyecto sin generar situaciones de conflictividad o tensión, y no se afecten derechos de comunidades e individuos. Es decir, si se practican adecuadamente técnicas de negociación, participación activa del titular minero, reconocimiento de la personería jurídica de la Comunidad Campesina y de su problemática, podemos decir que el negocio minero puede ser rentable y a la vez responsable.

\section{RETOS Y OPORTUNIDADES FUTURAS}

Los empresarios mineros peruanos tienen el reto de acercarse más a las entidades de la sociedad civil para lograr potencializar sus actividades de responsabilidad social. Asimismo, deben poner en práctica elementos y herramientas como el diálogo y el intercambio de información acerca de la problemática de la población o de las localidades donde se desarrollará el proyecto y acercarse a las autoridades locales en búsqueda de su involucramiento y aporte en el tema; al realizar estas acciones, podrían lograr mejores resultados de sus políticas corporativas sobre RSE.

Un reto a futuro muy importante consiste en promover la difusión de la RSE en los medios y comunidades académicas. Actualmente, existen pocas publicaciones especializadas en temas de RSE en el país, lo cual podría ser cambiado a través de la iniciativa de los medios en pro de difundir las actividades realizadas por empresas peruanas en este tema y que sirvan de modelo o réplica para otras empresas que se empiecen a involucrar en la responsabilidad social.

19 De manera adicional debemos advertir que este es el momento en el que se realizan negociaciones vinculadas no solo a la adquisición del terreno superficial, sino también de posibles afectaciones ambientales, reasentamientos, retribución por el uso de terrenos, establecimiento de compromisos y acuerdos, viabilidad de proyectos de desarrollo, posibilidades de trabajo en las instalaciones de la empresa, dinámicas sociales de vecindad, entre otras. 
El número de fundaciones existentes en el país ${ }^{20}$ es muy reducido y son muy pocas las empresas que tienen establecidos programas de donaciones y voluntariado corporativo dentro de sus actividades. Ello significa un reto para la empresa privada, sobre todo para las más grandes y sólidas del país, en lo que se refiere a la realización de obras sociales en temas de sociedad, género y medio ambiente.

El tema de la RSE no solo debe observarse como iniciativa de parte del sector empresarial privado, también debería considerarse desde el público. De esta manera, es conveniente que el Estado asuma el tema de la responsabilidad social dentro de su agenda para la ejecución de alianzas con el sector privado en pro de satisfacer las necesidades no cubiertas con la sociedad.

Así como los medios de comunicación cumplen un rol fundamental en la diseminación de actividades de responsabilidad social del sector privado y otras organizaciones, la comunidad académica debería incorporar estos temas dentro de los currículos profesionales de las carreras que imparten. Actualmente existen pocas universidades peruanas en las cuales se haya incorporado el tema de la RSE en la formación integral del alumno. Si bien es cierto que existen esfuerzos por parte de las universidades de dictar cursos libres sobre este tema, no debe dejarse de lado su incorporación en los cursos de carrera que permitan al alumno desarrollar una visión de la RSE no solo a nivel externo (aporte a comunidad y sociedad), sino conocer cómo se podría involucrar el tema desde la perspectiva interna de una organización.

La RSE es un tema desarrollado básicamente por las grandes empresas del país; sin embargo, las pequeñas y medianas empresas dejan de lado la incorporación de estas prácticas por el hecho de que "no cuentan con los recursos suficientes". Ello no debería ser una excusa para poder abarcar el tema en estas organizaciones, más bien debería ser un reto para que, con pocos recursos, se pueda desarrollar el tema hacia el interior y el exterior de las empresas. Para ello, es necesario que los pequeños y medianos empresarios se sensibilicen ante este tema y generen alianzas con otras empresas de la misma magnitud para probablemente desarrollar alternativas conjuntas en pro del desarrollo sostenible y la responsabilidad social.

Muchos empresarios peruanos han adoptado el tema de la RSE debido a las exigencias del mercado y de la normativa. Ello es un punto desfavorable, puesto que quedaría claro que el tema no estaría siendo desarrollado por convicción, sino por obligación o presión del entorno. Ante esta óptica, se hace necesario que la sensibilización de la RSE sea trabajada con más fuerza para lograr que las acciones emprendidas por los empresarios peruanos no sean solo palabras, sino acciones realizadas y asimiladas, no forzadas por el entorno.

20 Felipe Portocarrero y Cynthia Sanborn, Empresas, fundaciones y medios: la responsabilidad social en el Perú (Lima: Centro de Investigación de la Universidad del Pacífico, 2000), 222. 


\section{CONCLUSIONES}

- La Responsabilidad Social Empresarial, es un instrumento que vincula a la organización con sus trabajadores, sus familias y su entorno para que puedan trabajar sin problemas y vivir en armonía y tranquilidad. La encontramos enmarcada en la globalización, en el nuevo poder de los stakeholders, en la ética de las organizaciones, en el desarrollo de las tecnologías de la información y comunicación, en el cambio climático y problemas ambientales globales que hacen que la RSE esté en constante mejora continua, por el bien de las poblaciones y de la sociedad civil.

- La RSE está influenciada por factores externos de gran importancia que involucra a la sociedad, las crisis económicas, intereses particulares y políticos, crisis e incertidumbre política nacional, etc., elementos que intervienen constantemente en el desarrollo efectivo de la RSE que aplican las empresas mineras, lo cual genera muchas veces conflictos sociales.

- La Ley de Comunidades Campesinas establece que las comunidades campesinas son organizaciones de interés público, con existencia legal y personería jurídica, integradas por familias que habitan y controlan determinados territorios, ligadas por vínculos ancestrales, sociales, económicos y culturales.

- La actividad minera es uno de los pilares de la economía nacional y genera, en forma directa e indirecta, progreso y desarrollo económico para todo el país; sin embargo, en muchos de los casos, en las zonas alejadas donde se desarrollan los proyectos mineros, la población no siente los beneficios de la minería ni del desarrollo que esta actividad genera y es ahí donde de manera supletoria las empresas mineras, en algunos casos, contribuyen a atender las demandas de la población. Sin embargo, se sigue evidenciando conflictos y protestas sociales en torno a dicha actividad.

- El desarrollo adecuado de las técnicas de negociación, respeto por el entorno socioambiental, participación activa del titular minero y del Estado en las diversas modalidades de su institucionalidad, reconocimiento de la personería jurídica de la Comunidad Campesina y de su problemática permiten contar con la aprobación de la población para el desarrollo de un proyecto minero y garantizar de cierta manera que el negocio pueda ser rentable y a la vez responsable.

\section{RECOMENDACIONES}

- Se requiere establecer lineamientos mínimos para que las empresas elaboren los Planes de RSE equilibrados con los proyectos a desarrollar. Para ello, los empresarios tienen el reto de acercarse más a las entidades de la sociedad civil para lograr potencializar sus 
actividades de responsabilidad social. Asimismo, deben poner en práctica elementos y herramientas como el diálogo y el intercambio de información acerca de la problemática de la población o de las localidades donde se desarrollará el proyecto.

- Las universidades deben incorporar como parte de la formación de los profesionales cursos de RSE con el fin de asegurar un adecuado entendimiento y cumplimiento de los planes o programas y promover la investigación, capacitación y formación de los futuros profesionales en temas de RSE, con la finalidad de que las futuras generaciones conozcan los beneficios que produce la responsabilidad social.

- Se debe potenciar la relación Comunidad-Empresa-Estado y su capacidad de diálogo, a fin de generar confianza, indispensable para una relación empresarial con ausencia de conflictos. Esto significa un reto importante de interacción empresarial de modelo cooperativo en donde la empresa privada pueda realizar obras sociales en el marco de la RSE en temas de sociedad, género y medio ambiente, contando con el aval del Estado y de la misma comunidad.

- El tema de la RSE debe alejarse del criterio de que su cumplimiento obedece a las exigencias del mercado y de la legislación vigente, las políticas de RSE deben ser ejecutadas por convicción y no por obligación o presión del entorno. Por tanto, Estado y empresa privada deben sensibilizar los beneficios de la RSE para lograr que las acciones emprendidas por los empresarios peruanos no sean palabras o letra muerta en planes de gestión social y más bien se conviertan en acciones realizadas y asimiladas por las comunidades beneficiadas.

\section{REFERENCIAS}

- Cannon, Tom. La responsabilidad de la empresa. Respuesta a los nuevos retos sociales, económicos, éticos y de medio ambiente. Barcelona: Cannon Editores,1994.

- Corres Pedro. "Regulación y voluntariedad en la RSC". En Responsabilidad social corporativa, ed. por De la Cuesta, M. \& Rodríguez, L., 119-131 (2004).

- Diez Hurtado, Alejandro. Tensiones y transformaciones en comunidades campesinas. Lima: CISEPA, 2012.

- Franco Concha, Pedro. Diagnóstico de la responsabilidad social en el Perú. Lima: Centro de Investigación de la Universidad del Pacífico, 2007. 
- Garrigues, Antonio; Francisco Trullenque. "Responsabilidad social corporativa: ¿papel mojado o necesidad estratégica?". Harvard Deusto Business Review, nº 164 (2008).

- Herraz de la Casa, José María; Francisco Salinas Ramos. "La comunicación en el ámbito de la economía social”. En Colección Economía Social. España: Universidad Católica de Ávila, 2004.

- Lozano, Josep M. La empresa ciudadana como empresa responsable y sostenible. Madrid: Trotta, 2009.

- Martínez, Jennifer; Luis Vaquero Luis; Beatriz Cuadrado y María García. "El gobierno corporativo y la responsabilidad social corporativa en el sector bancario: El papel del consejo de administración”. Econstor 21 (2015): 129-138.

https://doi.org/10.1016/j.iedee.2015.01.001

- Montero Simó, José; Rafael Araque Padilla. La responsabilidad social de la empresa a debate. Barcelona: Icaria Editorial, 2006.

- Navarro García, Fernando. "Responsabilidad social corporativa: teoría y práctica”. Revista del Ministerio de Trabajo e Inmigración (2008).

- Perla, Cecilia. “¿Cuál es el destino de los países abundantes en recursos naturales?”. Documentos de Trabajo PUCP, no 242 (2005).

- Portocarrero, Felipe; Cynthia Sanborn. Empresas, fundaciones y medios: la responsabilidad social en el Perú. Lima: Centro de Investigación de la Universidad del Pacífico, 2000.

- Ramiro, Pedro. "Las multinacionales y la responsabilidad social corporativa: de la ética a la rentabilidad", en El negocio de la responsabilidad. Critica de la responsabilidad social corporativa de las empresas transnacionales, ed. por J. Hernández, \& P. Ramiro, 47-78. Barcelona: Icaria, 2009.

\section{Páginas web revisadas}

- García Paredes, Fabiola Lizzet. "La responsabilidad social en el sector minero y su incidencia en el manejo de los conflictos socioambientales en el Perú 2005-2013”. Acceso el 19 de noviembre del 2017. http://dspace.unitru.edu.pe/handle/UNITRU/995

- Garavito. "Desarrollo de una filosofía empresarial”. Acceso el 15 de julio de 2017. http://www.pucp.edu.pe/economia/pdf/DDD258.pdf 
- OIT. "Promulgación de Ley para la producción socialmente responsable a través de la instauración de una etiqueta voluntaria". Acceso el 15 de marzo de 2018. http://white.oit. org.pe/estad/laclispub/ndestacados/SOCIAL.pdf

- UNRC. "La población y el medio ambiente, América Latina - Nuestra región". Acceso el 27 de enero de 2019. https://www.unrc.edu.ar/publicar/19/dosier5.htm

- Pérez Ruiz, Wilfredo. "Responsabilidad social en el Perú". Blog personal. Acceso el 8 de abril de 2012. http://wperezruiz.blogspot.com/2012/03/la-responsabilidad-social-en-elperu.html 